\title{
The Effect of Health Quarantine on the Weight Control in Patients with Sleeve Gastrectomy in Comparison with Obese Patients without Surgery
}

\author{
Nashwan Q Mahgoob ${ }^{1,}$, ,Yasser F.Zidan ${ }^{2}$ and Muthanna A. AL-Sharbaty ${ }^{3}$ \\ ${ }^{1}$ Professor general surgery FACS. FICMS. Department of surgery College of medicine University of Mosul. \\ ${ }^{2}$ DOS. National Center of Obesity Specialist Surgeon \\ 3 Consultant Surgeon. FACS. FICMS. National center of obesity \\ *Corresponding author. Email: nashwanmahgoob1964@gmail.com
}

\begin{abstract}
Background: Most of the world's population underwent compulsory health quarantine during the pandemic of Coved 19 virus that led to a change in lifestyle and caused a negative psychological effect.

Objective: This study aims to assess the effects of different variables in lifestyle on the weights of obese patients who underwent sleeve gastrectomy compared to obese patients without surgery during 3 months of the health quarantine.

Methods: The study included 2 groups, the first one included 85 patients who underwent sleeve gastrectomy before more than 6 months since the date of the start of the health quarantine in Iraq. The second group included 75 patients with obesity but were not subjected to sleeve gastrectomy or any other bariatric surgery. Patients were contacted through social media 3 months after starting the health quarantine where the complete ban has ended, Patients were asked to answer an information form to assess their weight, nutritional state, commitment to diet, exercise performance and psychological mood during the quarantine time. A statistical study was conducted between the two groups.

Results: weight gain was recorded in both groups, although it is less in sleeved patients, the difference is not statistically significant. Physical exercises, altered diet habits, altered types of food were recorded in both groups and again without significant difference. Stress and altered sleep pattern which occurred in the quarantine may be attributed to weight gain. The study fails to show a significant relation to the special type of food.

Conclusion: weight gain recoded in Quarantine and this is a major health problem that may affect the life of obese patients.
\end{abstract}

Keywords: sleeve gastrectomy, COVID 19 virus, Quarantine, Weight, Bariatric.

\section{INTRODUCTION}

COVID- 19 expanded from an outbreak in China (December 2019) to a catastrophic pandemic all over the world; while the first case was reported in Iraq was on February 24th 2020, it takes about 1 month to record the 1st case in Mosul on 22nd of March [1]. Obesity is regarded as a global epidemic that may become pandemic after quarantine. In Iraq, more than two-thirds of people were overweight and obese [2]. There is a complex relationship between COVID 19 and obesity; obese people are more liable for infection with more morbidity and mortality also infected people are more liable to gain weight and the quarantine precaution results in obesity [3]. The health quarantine derived from the Italian, meaning "forty days", was used to isolate ships before passengers and crew could go ashore during the black death plague epidemic [4,5]. Despite being a way to avoid the spread of the disease, it has disadvantages [6]as it restricts the movement of the citizen and made them locked into the house, which changed their social, food, health, and sports behaviour. Certainly, the health quarantine affects obese patients, whether those who performed sleeve gastrectomy operations or who followed a food diet, as they moved away from the diet regime and began eating foods without caution 
and left the commitment to sports in addition to changing in their sleep pattern as well as not being easily able to communicate with their medical center for follow up $[7,8]$.

In this study, we try to shed light on the lifestyle variables that accompanied the health quarantine on the weights of patients with obesity, whether those

se series study conducted by two medical centers specialized in obesity management and care, the first in Erbil and the second in Mosul / Iraq in which two samples (160 patients) were chosen for the study. The first sample included patients who had sleeve gastrectomy operations more than 6 months before the who underwent surgery or who followed a diet by contacting the patients through social media and ask them to answer special format for evaluation of their weight.

\section{PATIENTS AND METHODS}

This is a prospective ca start of the health quarantine, and the second sample included patients with obesity that did not have any surgical intervention previously.

The study began after three months from the strict health quarantine (March 2020) in the two cities as life returned partially to normal after that. A sample of

Table 1. shows the mean weight and BMI of both groups before and after 3 months from quarantine.

group showed more commitment to sport than the

\begin{tabular}{|c|c|c|c|c|c|c|} 
Group no. & $\begin{array}{c}\text { Mean WT } \\
\text { before surgery }\end{array}$ & $\begin{array}{c}\text { Mean BMI } \\
\text { before surgery }\end{array}$ & $\begin{array}{c}\text { Mean WT } \\
\text { before quarantine }\end{array}$ & $\begin{array}{c}\text { Mean BMI } \\
\text { before quarantine }\end{array}$ & $\begin{array}{c}\text { Mean WT after } \\
\text { quarantine }\end{array}$ & $\begin{array}{c}\text { Mean BMI } \\
\text { after quarantine }\end{array}$ \\
\hline
\end{tabular}

\begin{tabular}{|l|c|c|c|c|c|c|}
\hline Group one & 118 & 38 & 90 & 31 & 112 & 32 \\
& $(98-146)$ & $(36-42)$ & $(78-110)$ & $(28-33)$ & $(80-116)$ & $(30-35)$ \\
\hline Group two & ----- & ------ & 102 & 37 & 133 & 41 \\
& & & $(90-140)$ & $(35-40)$ & $(93-150)$ & $36-41)($ \\
\hline
\end{tabular}

\section{RESULTS}

The study includes 160 patients, they were divided into 2 groups, group 1 included 85 patients with sleeve gastrectomy at least 6 months before the quarantine, their age range was 22 to 50 with a mean of 33 , there were 58 female and 27 male patients, group 2 included 75 patients with obesity (BMI more than $30 \mathrm{~kg} / \mathrm{m} 2$ ) without a history of bariatric surgery, their age ranges from 18 to 46 years and a mean of 32 years, it included 50 female and 25 male patients.

\subsection{Weight gain}

Occurs in both groups with an average of $22 \mathrm{~kg}$ in 1 st group versus $30 \mathrm{~kg}$ in the second which reflects on BMI increase of $1 \mathrm{~kg} / \mathrm{m} 2$ in 1 st group versus $4 \mathrm{~kg} / \mathrm{m} 2$ in the second and although the weight gain is less in the sleeved patient, this is not statistically significant (The chi-square is 0.0583 and $p$-value is 0.809136 as shown in table (1) and figure (1).

\subsection{Exercise performance}

Varies from regular daily activity to 2 to 3 times a week to nil per week; patients explained the inability to perform sports due to the lack of a suitable place or home appliances in addition to joint pain and lack of desire to do so. Those with the sleeve gastrectomy second group, but again the difference is not statistically significant. The chi-square is 3.0524. The p-value is 0.080618 as shown in table 2 and figure (2).

\subsection{Especial regimen}

Both groups had difficulty following special regimen during the quarantine, but we found that group one is more committed to the regime than group two although the difference is not statistically significant (chi-square is 3.3813 and p-value is 0.065941 ) as shown in table 3 and figure (3).

\section{BMI changes in both Groups}

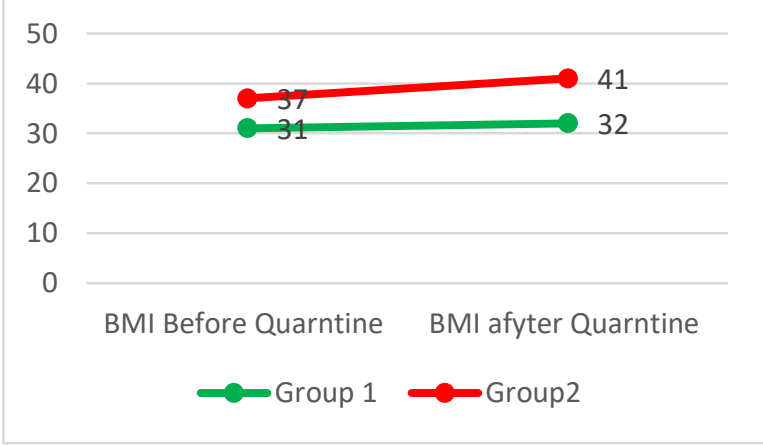




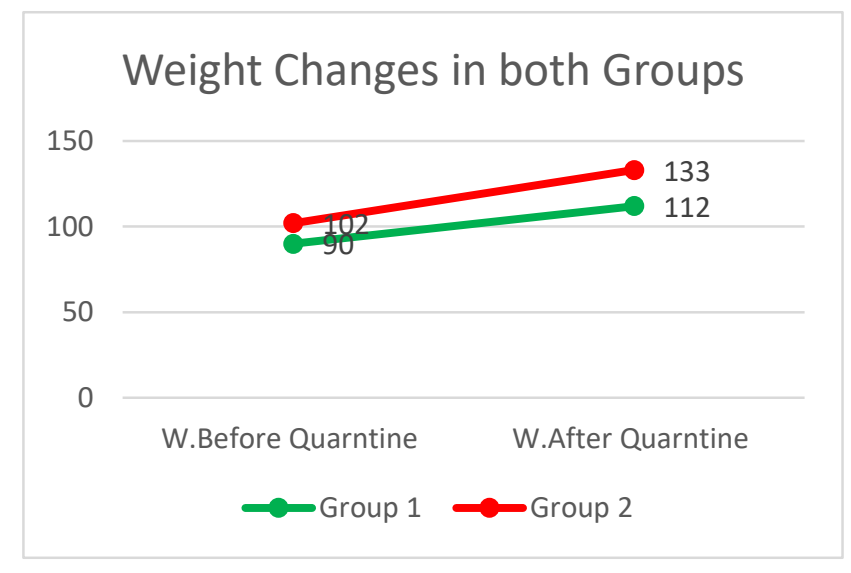

Figure 1 Shows the mean weight and BMI of both groups before and after 3 months from quarantine.

Table 2. performing physical exercise

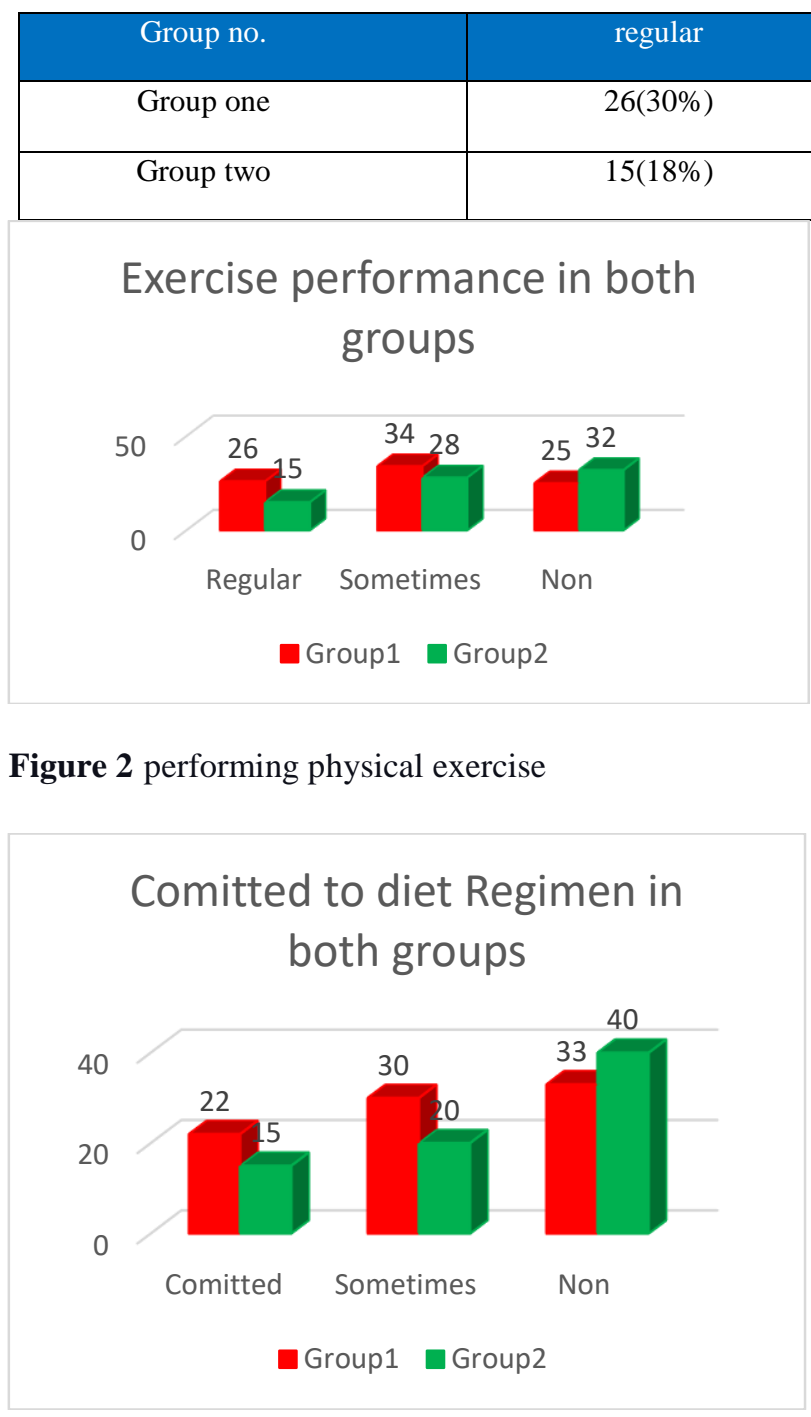

Figure 3 Following special regime by the patients

\begin{tabular}{|l|c|}
\hline Some time & non \\
\hline $34(40 \%)$ & $25(30 \%)$ \\
\hline $28(37 \%)$ & $32(43 \%)$ \\
\hline
\end{tabular}

\subsection{Change in food pattern}

During quarantine was found in both groups, the second group appeared to be more interested in changing the eating style, they attributed that for a long time sitting at home watching TV, playing games, chatting or reading as shown in table 4.

The details about types of food eaten by the patients through the week, as shown in table 5 using analysis of variance ANOVA shows that there is no statistical difference between both groups with a pvalue of 0.538 .

\subsection{Comorbidity}

None of the patients in both groups was suffered from any chronic or annoying gastro-intestinal condition; there were 23 hypertensive and 17 diabetic patients in group one and 33 hypertensive and 28 diabetic patients in the group, most of them were under medication.

\subsection{Sleep Pattern}

sixty patients $(70 \%)$ in group one and 55 patients (73\%) in group two complained of changing the sleep pattern as they were waking up late hours due to the lack of important work and the inability to sleep early. The psychologically stressful feeling during the health quarantine was found in a high number in both groups, it was in 55 patients $(65 \%)$ in group one and 48 patients $(64 \%)$ in group two. 


\subsection{Medical counselling}

Lockdown involved most of the cities including the health place like clinics and medical centers, it became difficult to communicate directly with the doctor and contact was limited to the phone and social networks, 60 patients (70\%) from the first group identified interaction and communication with their medical center, while only 33 patients (44\%) from the second group achieved communication.

\section{DISCUSSION}

Quarantine is one of the most important steps to control the spread of deadly COVID-19 which was first diagnosed in Wuhan-China [9]it was recommended by WHO in addition to isolation, use of Personal Protective Equipment(PPE) and social distancing $[10,11]$.

During health quarantine, universities, schools, travels, businesses, cafes, casinos, parks, gyms and cinemas were all closed, restaurants and take-away offers were limited and supermarkets became less available and outdoor movement became so restricted. Such lifestyle changes surely, harm the physical and mental health of the person and may translate into a range of emotional reactions including stress, depression, irritability, insomnia, fear and psychiatric conditions [12]. Some individuals may be more vulnerable than others to these psychosocial effects, in particular, people who contract the disease or one of their family, patients with immunity suppression, old age persons, those who need medical care as well as those with obesity [13], so it is easily understandable that lockdown and quarantine harmed the health and this study shows that weight gain occurred in most patients including those with sleeve gastrectomy although they gain less weight as compared with patients without surgery, this difference is not significant statistically.

Weight gain may be attributed to decrease physical activity that accompanied quarantine and only a few patients were committed with regular exercise and these results were comparable with Luc Goethals from France [14], Micheal [15], Yafit [16] and the largest study by Onno et al with more than 4000 patients[17], this can be explained by the fact that people staying home and engaging in online working learning and communicating with others but may not be able to follow their normal routines for exercise; this may be attributed to many causes, first of all, is that the outdoor sports centers and gyms which provide an atmosphere that encourages fitness, motivates people, have more facilities and infrastructures to perform any type of physical exercise apart from the presence of professional trainers and followers were officially closed during the health quarantine. There still are many possibilities for exercising at home but this does not have large equipment or specific materials for training. Secondly, staying at home for prolonged periods can pose a significant challenge for remaining physically active, makes the person addicted to laziness and lack of interest in sports, this sedentary behaviour and low levels of physical activity can have negative effects on the health and body weight.

Bariatric Surgery has no effect on food preferences, but personal changes in food preferences may predict weight loss [18] and this study shows that quarantine has a bad effect on diet habits with the increase in snacks and alteration of types of food and the statistical test of analysis of variance shows no significant relation to the specific type of food which is comparable with Moser F et al. and Hudson SM $[19,20]$, while Hamed A. and Figura reported an adverse effect on weight loss and even weight gain related to sweet eater [21,22,23]; Most of these unhealthy habits of eating with unhealthy types of food was aggravated by quarantine and these results are comparable with Giovanna [24]and Anna et al [25]. This change and inability to control diet habits weren't seen before quarantine [26] and this can be explained as sitting home makes people more interested in changing eating style, and more TV watching, playing games, chatting or reading.

The absence of direct visits and follow up (no medical counselling) may negatively affect weight loss as shown in this study and these are also mentioned by David Martin (26) and Yafit Kessler [16].

Comorbidity may affect weight loss and this study shows that 56 patients had hypertension that may decrease weight loss which was comparable with David Martin [26]; this with limited activities leads to overeating, many families are obligated to spend more time at home, which provides new opportunities to prepare and share meals in favour of high fat and sugar content, even in the absence of hunger and lack of need for calories [27]; this effect may be exacerbated in overweight or obese individuals as compared to lean individuals[28].

Stress is inevitable both due to the pandemic and quarantine and it's well-known that stress (acute and chronic) may influence multiple appetite-related hormones that cause more food consumption and subsequent weight gaining $[29,30]$.

This study demonstrated that $57 \%$ in the first group and 69\% in the second group showed sleep disturbance during the health quarantine and this may be attributed to weight gain. [31,32]. 


\section{CONCLUSION}

Weight gain recoded in Quarantine and this is a major health problem that may affect the life of obese patients. This study shows that weight gain accompanied quarantine in Iraq even in patients who had bariatric surgery and these results are comparable with the Polish experiment [33] and the Italian experience as there is some similarity with our Mediterranean type of food.

\section{Statistical analysis}

All the data has been edited, processed and analyzed by the use of statistical software package SPSS version 20.0 (SPSS Inc., Chicago, ILL) and GraphPad online calculator; A p-value $\leq$ of 0.5 was considered statistically significant.

Table 3. Following special regime by the patients

\begin{tabular}{|c|c|c|c|}
\hline Group no. & yes & Some time & non \\
\hline Group one & $22(26 \%)$ & $30(35 \%)$ & $33(39 \%)$ \\
\hline Group two & $15(20 \%)$ & $20(27 \%)$ & $40(53 \%)$ \\
\hline
\end{tabular}

Table 4 change of food pattern.

\begin{tabular}{|c|c|c|c|}
\hline Group no. & Unable to control eating & Not restrict to usual meals & Eating between major meals \\
\hline Group one & $34(40 \%)$ & $26(30 \%)$ & $38(45 \%)$ \\
\hline Group two & $40(53 \%)$ & $36(48 \%)$ & $50(66 \%)$ \\
\hline
\end{tabular}

Table 5 types and frequency of food eaten

\begin{tabular}{|l|c|c|c|c|c|c|}
\hline \multicolumn{1}{|c|}{ Food type } & \multicolumn{3}{|c|}{ Group one (85 pt) } & \multicolumn{3}{c|}{ Group two (75 pt) } \\
\hline & daily & frequent & not & daily & frequent & not \\
\hline Red meat & $30(35 \%)$ & $40(47 \%)$ & $15(18 \%)$ & $25(33 \%)$ & $40(53 \%)$ & $10(14 \%)$ \\
\hline chicken & $15(18 \%)$ & $42(50 \%)$ & $27(32 \%)$ & $35(47 \%)$ & $27(36 \%)$ & $13(17 \%)$ \\
\hline fish & $10(12 \%)$ & $28(33 \%)$ & $47(55 \%)$ & $15(20 \%)$ & $40(53 \%)$ & $20(27 \%)$ \\
\hline Vegetables & $80(95 \%)$ & $5(5 \%)$ & 0 & $75(100 \%)$ & 0 & 0 \\
\hline fruit & $75(88 \%)$ & $10(12 \%)$ & 0 & $70(93 \%)$ & $5(7 \%)$ & 0 \\
\hline White wheat & $20(24 \%)$ & $38(44 \%)$ & $27(32 \%)$ & $18(24 \%)$ & $40(54 \%)$ & $17(22 \%)$ \\
\hline rise & $15(18 \%)$ & $48(57 \%)$ & $22(25 \%)$ & $50(66 \%)$ & $14(19 \%)$ & $11(15 \%)$ \\
\hline sweets & $10(12 \%)$ & $38(44 \%)$ & $37(44 \%)$ & $30(40 \%)$ & $35(47 \%)$ & $10(13 \%)$ \\
\hline dairy & $60(70 \%)$ & $25(30 \%)$ & 0 & $55(74 \%)$ & $20(26 \%)$ & 0 \\
\hline beverage & $14(17 \%)$ & $45(53 \%)$ & $26(30 \%)$ & $23(30 \%)$ & $40(54 \%)$ & $12(16 \%)$ \\
\hline alcohol & 0 & $5(6 \%)$ & $80(94 \%)$ & 0 & $8(11 \%)$ & $67(89 \%)$ \\
\hline Processed food & $33(35 \%)$ & $30(35 \%)$ & $25(30 \%)$ & $37(50 \%)$ & $28(37 \%)$ & $10(13 \%)$ \\
\hline
\end{tabular}

\section{REFERENCES}

[1] Epidemiological Features of COVID-19 Epidemic in Basrah Province-Southern Iraq-First Report. Omran S Habib., Abbas K AlKanan., Alaa H Abed, et al. 1, s.l.: The Medical Journal of Basrah University, 2020, Vol. 38. 6-17.

[2] Preliminary Experience of Sleeve Gastrectomy. Muthanna A.Al-Sharbaty, Yasser F.Zidan ,Samir
I. Al-Saffar ,et al. 3, s.1. : THE IRAQI POSTGRADUATE MEDICAL JOURNAL, 2016, Vol. 15. 350-354.

[3] Influenza and obesity: its odd relationship and the lessons for COVID-19 pandemic. Livio Luzicor., Maria Grazia Radaelli. s.l. : Natire Public Health Emergency Collection, 2020, Vol. 5. 1-6. 
[4] The origin of quarantine. P.A., Mackowiak. s.l. : Clin Infect Dis., 2002, Vol. 35. 1071-1072.

[5] Shutt up: bubonic plague and quarantine in early modern England. K, Newman. s.l. : J Sol Hist., 2012, Vol. 45. 809-834.

[6] Systematic Rapid "Living" Review on Rehabilitation Needs Due to covid-19: Update to March 31st 2020. Maria G Ceravolo, Alessandro De Sire, Elisa Andrenelli, et al. s.l. : Eurpean Journal of Physical and Rehabitaional Medicine, 2020. 253.

[7] Aten up by boredom: consuming food to escape awareness of the bored self. Moynihan AB, van Tilburg WAP, Igou ER, Wisman A, Donnelly AE, Mulcaire JB. E. 2015;6:369. : Front Psychol. , 2015, Vol. 6. 369.

[8] Variety Is the Spice of Late Life: Social Integration and Daily Activity. Fingerman KL, Huo M, Charles ST, Umberson DJ. 2, s.1. : The Journals of Gerontology: Series B, 2020, Vol. 75. $377-388$

[9] The deadly coronaviruses: The 2003 SARS pandemic and the 2020 novel coronavirus epidemic in China. Yongshi Yang, a, Fujun Peng,b,c, Runsheng Wang,et al. s.l. : J Autoimmun., 2020, Vol. 109. 102434.

[10] Efficiency of quarantine during an epidemic of severe acute respiratory syndrome-Beijing, China. MMWR. Prevention, Centers for Disease C. and. 43, s.l. : Morbidity Mortality Weekly Report, 2003, Vol. 52. 1037-1040.

[11] Quarantine alone or in combination with other public health measures to control COVID-19: a rapid review. Barbara Nussbaumer-Streit, Verena Mayr , Andreea Iulia Dobrescu, et al. 4, s.l. : Cochrane Database of Systemic Revews, 2020, Vol. 8. (4):CD013574. doi: 10.1002/14651858.CD013574.

[12] The psychological impact of quarantine and how to reduce it: rapid review of the evidence. Samantha K Brooks, Rebecca K Webster, Louise E Smith,et al. s.l. : Lancet, 2020, Vol. 395. 91220.

[13] System effectiveness of detection, brief intervention and refer to treatment for the people with post-traumatic emotional distress by MERS: a case report of community-based proactive intervention in South Korea. Mi-Kyung Yoon, Soon-Young Kim , Hye-Sun Ko,et al. 10, s.1. : Int J Ment Health Syst., 2016, Vol. 8. 51.
[14] Impact of Home Quarantine on Physical Activity Among Older Adults Living at Home During the COVID-19 Pandemic: Qualitative Interview Study. Luc Goethals, Nathalie Barth, Jessica Guyot, et al. 1, s.l. : JMIR Aging., 2020, Vol. 3. e19007.

[15] Postoperative Outcomes, Weight Loss Predictors, and Late Gastrointestinal Symptoms Following Laparoscopic Sleeve Gastrectomy. Michael Goldenshluger, Ariela Goldenshluger, Lital Keinan-Boker et al. https://doi.org/10.1007/s11605-017-3585-9, s.1.: J Gastrointest Surg, 2017, Vol. 21.

[16] Associations of dietitian follow-up counselling visits and physical exercise with weight loss one year after sleeve gastrectomy. Yafit Kessler, Liraz Olmer, Asnat Raziel, et al. 1, s.l. : Eat Weight Disord, 2020, Vol. 25. 1430150.

[17] Increase in Physical Activity After Bariatric Surgery Demonstrates Improvement in Weight Loss and Cardiorespiratory Fitness. Onno M Tettero, Tianna Aronson, Rens J Wolf ,et al. 12, s.1. : Obes Surg, 2018, Vol. 28. 3950-3957.

[18] Bariatric Surgery Does Not Affect Food Preferences, but Individual Changes in Food Preferences May Predict Weight Loss. Mette Søndergaard Nielsen, Simone Rasmussen, Bodil Just Christensen,et al. 12, s.l. : Obesity Society , 2018, Vol. 26. https://doi.org/10.1002/oby.22272.

[19] Sweet eating habit: does this affect the results after sleeve gastrectomy? Moser F, Marconetto M, Gorodner V, Viscido G, Piazzoni N, Maldonado P, et al. 4, s.l. : J Laparoendosc Adv Surg Tech A., 2016, Vol. 26. 270-275.

[20] Sweet eating is not a predictor of outcome after Lap-Band placement. Can we finally bury the myth? . Hudson SM, Dixon JB, O’Brien PE. 6, s.1. : Obes Surg, 2002, Vol. 12. 789-794.

[21] Revisional Laparoscopic Sleeve Gastrectomy in failed gastric banding and effects of exercise and frequent sweet-eating on its outcome. Hamed A. AlWadaani, and Abdul Qadeer. 3, 2017, Vol. 33 524-528

[22] Hanges in self-reported eating patterns after laparoscopic sleeve gastrectomy: a pre-post analysis and comparison with conservatively treated patients with obesity. . Figura A, Rose M, Ordemann J, Klapp BF, Ahnis A. 2, s.1. : Surg Obes Relat Dis., 2017, Vol. 13. 129-137.

[23] Nutritional recommendations for CoVID-19 quarantine. Giovanna Muscogiuri, Luigi Barrea, 
Silvia Savastano, et al. s.1.: Eur J Clin Nutr. , 2020, Vols. doi: 10.1038/s41430-020-0635-2.

[24] "Quarantine during COVID-19 outbreak: Changes in diet and physical activity increase the risk of cardiovascular disease". Anna V. Mattioli, Susanna Sciomer, Camilla Cocchi, et al. s.l.: Nutr Metab Cardiovasc Dis., 2020, Vol. oi: 10.1016/j.numecd.2020.05.020.

[25] Changes in self-reported eating patterns after laparoscopic sleeve gastrectomy: a pre-post analysis and comparison with conservatively treated patients with obesity. Andrea Figura, Matthias Rose, Jürgen Ordemann,et al. 2, s.l. : Surg Obes Relat Dis, 2017, Vol. 13. 129-137.

[26] Predictors of weight loss 2 years after laparoscopic sleeve gastrectomy. David J Martin, Crystal MY Lee ,Georgia Rigas, et al. 3, s.l. : Ascian Journal of Endoscopic surgery, 2015, Vol. 8. 328-332.

[27] Food selection changes under stress. 2006 Apr 15; 87(4):789-93. Ellner DA, Loaiza S, Gonzalez Z, Pita J, Morales J, Pecora D, Wolf A. 4, s.l. : Physiol Behav., 2006, Vol. 87. 789-93.

[28] Psychosocial stress and change in weight among US adults. Block JP, He Y, Zaslavsky AM, Ding
L, Ayanian JZ. 2, 2009 Jul 15; 170(2):181-92. : Am J Epidemiol. , 2009, Vol. 120. 181-92.

[29] Dissociation between reactivity of the hypothalamus-pituitary-adrenal axis and the sympathetic-adrenal-medullary system to repeated psychosocial stress. . Schommer NC, Hellhammer DH, Kirschbaum C. 3, s.l. : Psychosom Med., 2003, Vol. 65. 450-460.

[30] Relationship between stress, eating behaviour andobesity. Torres SJ., Nowson CA,. 11-12, s.1. : Nutrition, 2007, Vol. 23. 887-94.

[31] Review association between sleep loss and increased risk of obesity and diabetes. Knutson KL, Van cauter E. s.1. : Ann N Y Acad Sci, 2008, Vol. 1129. 287-304.

[32] Short sleep duration and weight gain: a systematic review. patel SR, Hu FB. 3, s.l.: Obes Surg, 2008, Vol. 16. 643-53.

[33] Dietary Choices and Habits During COVID-19 Lockdown: Experience from Poland. Aleksandra Sidor, Piotr Rzymski. 6, s.1. : Nutrients, 2020, Vol. 12. E1657. doi: 10.3390/nu12061657.

[34] Eating habits and lifestyle changes during COVID-19 lockdown: an Italian survey. 229, s.1. : J Transl Med, 2020, Vol. 18. doi: 10.1186/s12967-020-02399-5. 